\title{
DEVELOPING AN ONLINE CURRICULUM FOR AN INTERNATIONAL AND INTER-DISCIPLINARY MASTER PROGRAMME. A CASE REPORT OF A DAAD FUNDED PROJECT IN GERMANY
}

\author{
Ly Lutter ${ }^{1}$, Sabrina A. L. Frohn², Mishael Gabrielle Pizana Cruz ${ }^{2}$ and Tobias Thelen ${ }^{1}$ \\ ${ }^{I}$ Center for Digital Teaching, Campus Management and Higher Education Didactics; Institute of Cognitive Science, \\ Osnabrück University, Germany \\ ${ }^{2}$ Institute of Cognitive Science, Osnabrück University, Germany
}

\begin{abstract}
This paper describes the methodology of the ongoing efforts to design and integrate an online curriculum as an additional track to an existing, well-established interdisciplinary master programme for international students studying remotely and asynchronously with on-site students. We aspire to integrate online teaching and learning into in-person lectures so that both online and on-site students profit from the joint educational experience. During the initial orientation, we conducted a field-based investigation to define the problem, analysed the context, and assessed needs of the involved stakeholders. Prominent outputs of this phase were a literature review, a SWOT analysis of the target setting, a synopsis of stakeholder needs and wishes, and course goals. This enabled us to devise communication strategies with the stakeholders, define learning objectives, and course transformation plans to feed the design of new learning scenarios combining elements of online teaching and learning (OTL) with traditional on-site teaching. These integrate into communication tools that build on mixed student teams of online and on-site students working collaboratively.
\end{abstract}

\section{KEYWORDS}

Curriculum Design, Educational Design, Virtual University, Distance Learning

\section{INTRODUCTION}

This project, funded by the German Academic Exchange Service (DAAD), aims to make German study programs more internationally competitive and attractive to previously excluded target groups. For integrating online teaching and learning into in-person educational practices, we plan to instantiate work forms, such as assignments or groupwork that utilize the benefits of the international and asynchronous setting. In particular, we aim to take advantage of the slow but reflective nature of written communication and the diverse academic backgrounds of students for facilitating cognitive presence and student engagement.

Conclusively, we are developing new learning scenarios in close collaboration and alignment with the instructors' requirements and their course goals. Firstly, we utilize communication tools such as chats and threaded discussions to facilitate interaction among course participants and instructors. Secondly, we build on mixed student teams of online and on-site students who work on joint assignments and receive mentoring and exercise peer counselling on study progress, study goals and career perspectives in our overall design of the online study programme.

The rationale for the different steps and perspectives that must be considered for sound curriculum development on a global level was provided by McKenney and Reeves (2012). In order to explain why and how the instructional design process should be undertaken on the course level, we designed backwards as proposed by Wiggins and McTighe (2008). First, we identified what students should understand and be able to accomplish according to instructors, the module handbook and course materials. Secondly, we then identified what the instructors would accept as evidence of student understanding and their ability to use their learning in new and authentic situations (Wiggins \& McTighe, 2008). The targeted courses are centred around programming, mathematics and neuroscience, which are the most popular among international students. 
All six courses are based on lecture recordings and slides provided by the course instructors and some feature student-generated summaries and study material as products of assignments from previous teaching cycles.

\section{INITIAL ORIENTATION AND FIELD-BASED INVESTIGATION}

The results of our field-based investigation (SWOT analysis of the target setting, a synopsis of the stakeholder needs and wishes) and the literature review for the curriculum design process culminate in a problem definition and long-range goal. This initial orientation issued the design requirements and propositions for transforming the first six courses that were traditionally taught in an in-person lecture format to hybrid courses. To that end, we met with the instructors and addressed the official project goals while gauging their attitudes, values, and interests. Moreover, in order to collect perceptions about current online teaching and learning, we interviewed the involved stakeholders from the institute which include the student body, the study programme coordinator, the subject-specific mentoring team, and the university vice president. Additionally, we conducted a policy synthesis of the existing module handbook and investigated general and subject-specific student evaluations of the previous online corona semester. Our endeavour was led by efforts to determine how instructors, students, and stakeholders within the university system experienced the integration of OTL and / or what they suspect as the causes for its' scarcity (McKenney \& Reeves, 2012). Further, we placed high importance on elucidating the needs and wishes of the involved parties to digitalize the courses in alignment with the individual teaching style and teaching capacities as well as what students and instructors would desire for OTL (McKenney \& Reeves, 2012). Based on these insights, we synthesized a problem definition and designed measures which promote self-directed learning (Ke, 2010) and the establishment of a community of inquiry (Rubin et al., 2013).

Currently, the (online) educational practice significantly lacks social and intellectual interaction among students, between students and instructors, and between the German and the international student group. The courses are based on unspoken expectations regarding prior knowledge and skills that are shaped/ formed by cultural norms and habits. For example, "basic math" implies German Abitur-level math skills, which is not clearly stated nor necessarily comparable for internationals. This points to a systemic problem for international students in learning and integrating into the community. Furthermore, instructors have difficulties assessing students' needs and detecting and correcting misconceptions in students' understanding. The instructors express that they do not know how to engage students. While there seems to be insufficient resources for designing and facilitating learning activities that foster higher-order-thinking, a discrepancy seems to exist between the desire to discuss with students and the time constraints of instructors. Many lectures lack scaffolds for student learning such as clear instructions, advice on how to work in groups, or how to approach tasks that support students to move in their zone of proximal development (Vytgosky, 1978). Further, students report that some assignments are very artificial and that they experience uncertainty and confusion as to what is expected of them. For example, there are instances when students do not know how to apply theory to coding assignments. Instructors are not satisfied with students' knowledge transfer and scientific skills, which was visible in the drop of exam results and student interactivity in the past corona-semester. Yet, students focus on learning for the test and not on learning for understanding because of the high amount of content, which is partially also due to students taking too many courses at once.

By analyzing our interview notes in a SWOT analysis, we identified the jurisdiction of change, which revealed a clear understanding of strengths (e.g. students like self-directed and group-based learning, all instructors seek new methods for social interaction with students), weaknesses (e.g. instructors' partial unawareness for the need for informal communication between instructors and students, leading to uncertainty about students learning journey and students becoming passive consumers of content), opportunities (e.g. technical facilities and educational methods are available) and threats (students must learn and be supported to adapt to online learning, cultural mismatch and (implicit) biases regarding international students within the context of the study programme) that mitigate/contribute to the problem or even might facilitate/hinder a solution. By these means, we were able to study the formal, perceived, and enacted curriculum, which facilitated hypotheses about the factors that determine the implementation and spread of the digital curriculum. Utilizing the different strategies and methods served a balanced portrayal of the situation, created a broader ownership for the project, enabled respondent triangulation (McKenney \& Reeves, 2012), and shaped our literature review which we wrote simultaneously. 


\section{SCRUTINIZING SELF-DIRECTED LEARNING AND A COMMUNITY OF INQUIRY}

We aim to integrate online teaching and learning within on-site educational practices of a higher education institution and establish a community among the whole student body. Therefore, we use a framework that offers guidance for: (1) Designing asynchronous online learning experiences where there is a poverty of social signals (tacit signs of approval, understanding, or puzzlement) and that address the need to assure new ways to communicate and interact (Berge, 2008); (2) using self-directed learning as a lens to address adult learning in higher education and asynchronous learning settings. This supports student success in distance learning and offers flexibility regarding time, pace, and location that learners need due to the partially asynchronous setting (Bailey \& Card, 2009; Kebritchi et al., 2017).

We analysed the existing courses and teaching practices regarding the facilitation of self-directed learning to accommodate the needs of online adult students, as SDL is a prominent concept for adult learning and for assessing and facilitating online learning in remote teaching and learning circumstances (Bailey \& Card, 2009; Ke, 2010; Martin et al., 2019). Knowles (1992) (Bailey \& Card, 2009) defines self-directed learning as a process in which learners take responsibility for diagnosing their learning needs, establishing learning goals, implementing learning strategies, identifying the human and material resources for their learning, and evaluating their learning outcomes. Further, we analysed and redesigned the courses using the Community of Inquiry (CoI) framework because it integrates constructivist and self-directed learning paradigms and highlights the importance of an online learning community (Garrison et al., 1999). The CoI outlines the three elements teaching, social and cognitive presence. These elements and their overlaps provide "the structure to understand the dynamics of deep and meaningful online learning experiences" (Garrison et al., 2010, p. 32). Moreover, the CoI offers a structured approach to assess the enlivenment of each of the presences (Garrison et al., 2001; Garrison et al., 2010).

\section{INTEGRATING ONLINE TEACHING AND LEARNING INTO CURRENT IN-PERSON TEACHING PRACTICES}

The instructors emphasized the importance of student understanding, interaction and communication with and among students and scalability of assessment methods for the course transformation, so we are closely collaborating with the instructors to identify the (1) links between concepts and conclusions students should draw and remember after they have forgotten most of the details, (2) the prerequisite knowledge and skills to arrive at these conclusions and (3) subject matter that is worth being familiar with (Wiggins \& McTighe, 2008). With this lens on the courses, we are currently developing thought-provoking, open-ended questions that require justification and raise additional questions (Wiggins \& McTighe, 2008) to facilitate cognitive and behavioural engagement in written discussion forums.

Furthermore, all instructors addressed the importance of student understanding, interaction and communication with and among students and scalability of assessment methods. All lecturers sought new methods to facilitate student engagement and expressed a desire to communicate with the students in order to gauge what the students are doing or whether they understood the subject correctly. Hence, student behavioural, cognitive and affective engagement in online courses were stipulated as goals of the integration of the online into the in-person lecture (Bond et al., 2020; Galikyan \& Admiraal, 2019), as well as communicative measures that acknowledge the new roles and responsibilities instructors and students have in these hybrid teaching formats (Bailey \& Card, 2009; Berge, 2008; Galikyan \& Admiraal, 2019; Kebritchi et al., 2017) and clear instructions to scaffold students' learning, especially during group work (Molenaar et al., 2014). We identified the informal hallway chatter and missing role models for academic approaches to scientific inquiries by instructors in in-presence lectures to be one of the most substantial differences for cognitive presence in online learning scenarios. In online scenarios, students are not exposed to the habitus and behaviour of scientists like they would be when being in the same room, such that this vacuum needs to be filled or compensated. The next paragraph describes the measures we designed to address the identified gaps between online and in-presence teaching formats. 


\subsection{Designing Measures to Promote Student Engagement and Self-Directed Learning in a Community of Inquiry}

We instantiated instructor-monitored, low threshold communication with course spaces and topical channels (chatrooms) in an instant messaging client (Element) to facilitate co-construction of meaning in a learning community. In these channels, we highlight critical reflection and discourse. Links on top of the forum titled "How do I write a good post?" or "Do's \& Don't's" guide students when using and leveraging the discussion forums for the greatest learning benefit. These discussion channels pose the infrastructure to interact and monitor the integration and resolution level of cognitive presence for instructors, which will be utilized to uncover and correct misconceptions of students. The purpose of instructional and educational measures is clearly communicated to students in a timely manner within the LMS as suggested by Van der Meij and Carroll (1995). Furthermore and for the first time, students will receive syllabi which synthesize all necessary information about the courses, as suggested by Galikyan and Admiraal (2019). To that end, we filtered out learning objectives from course material to address students' confusion. The learning objectives convey what is expected of students to focus on (Wunderlich \& Szczyrba, 2016). These expectations are clearly communicated at the beginning of every unit in the LMS so that students can self-monitor their learning. Moreover, we synthesized the expectations of instructors, the instructional modality, teaching philosophy and assignment instructions which communicate evaluation criteria and clear objectives including checklists for submission in the course syllabi for every course. Further, micro lectures were generated from 90-minute lecture recordings which consider cognitive load theory (Jong, 2010; Star \& Stylianides, 2013) and student engagement (keeping it brief and using a conversational style for the newly recorded videos). Additionally, we promote active learning by embedding the micro lectures into a meaningful context as suggested in a review by Brame (2016).

In order to move from a passive to a more active learning experience, we designed short activities that accompany these newly created micro lectures to facilitate cognitive engagement and made the micro lectures part of larger homework assignments aiming to increase the sensibility of the micro lectures (Brame, 2016; Hung et al., 2010). Aside from the technical and subject matter transformation of course content, we placed high importance on scaffolding the students' learning journey. We situated the different elements of the courses (micro lectures, activities, discussion prompts, discussion infrastructure, assignments, evaluation criteria) in a structured and self-explanatory fashion within the LMS, following minimalist design principles to address self-directed learning (Kebritchi et al., 2017; Van der Meij \& Carroll, 1995). Considering the Community of Inquiry, these means targeted enhancing cognitive, social and teaching presence.

\section{CONCLUSION}

The current project describes the ongoing efforts to design and implement an online track from existing courses of an on-site study programme for international students. The first project cycle has demonstrated the importance of sensibly merging both analytical and creative perspectives. These perspectives allow us to understand the current situation in which the project resides and discover opportunities to leverage the project goals. The various endeavours require systematic, focused and open-minded activities at the same time which often are inseparable from each other. In our experience, well-prepared interviews and careful listening to both systematic issues as well as personal interests were most insightful and provided a fruitful basis for the ongoing collaboration. To that end, we intensively studied the material of the courses. Our team attitude to be sincerely and genuinely interested in the experiences and needs and wishes of the instructors as well as the online students, established the grounds for constructive discussions on how and why current teaching practices unfold as they do. We addressed the teaching experiences, scarce time and pedagogical knowledge of instructors by clear and transparent communication, i.e. informing instructors about frameworks we would use to understand and revise current teaching practices and communicated the links of these frameworks to their own requirements and the project goal. Student assistants who were onboarded after the initial orientation (who studied online in the past semesters in this study programme) confirmed the problem statement. This confirmation acknowledged the analysis to be a concise and accurate reflection of their impressions of the current situation of teaching and learning. According to the instructors, we were able to suggest new learning activities that address the course goals and adhere to their requirements of scalability and manageability such 
as group assignments which are revised based on peer review and clear evaluation criteria. Taken together, this feedback suggests that the educational transformation of courses to OTL requires a field-based investigation utilizing different methods for phrasing an accurate problem statement and a profound overview about current research on the themes that emerge from the project goals and the initial orientation. The literature review in particular not only serves understanding but also inspires the design of educational measures.

Given the very ambitious time plan of having to transform a whole master study programme within two years, it was a challenge to resist the urge to act without having understood the causes and goals. This required thorough communication about the educational design steps and trust in the team. Despite that, constant efforts had to be put into sensitively navigating between the instructors' enthusiasm to transform a course to completely being held online and their scarce availability. Whilst the course design was traditionally guided by textbook coverage, our backwards design approach was admittedly well-taken, but with a certain amount of discomfort given the effort it entails. Thus, we offered support in all tasks and condensed as much information as possible from the available material (presentation slides, lecture recordings and interviews) to arrive at course goals and learning objectives. Our team served not only as a help desk but also as institutional support for transforming the courses which we view as a critical success factor. Based on the courses' purposes and big ideas, we created demo versions of one unit that include contextualized blanks which illustrated what kind of information and actions were still necessary for the instructors to do. This approach was extremely successful because it inspired the instructors to think of their own courses with new eyes. The design of the demo courses facilitated to think from the student's perspective because we addressed the needs and wishes of the instructors to (1) improve student understanding and facilitate deep learning, (2) facilitate interaction and communication with students that allows instructors (3) to keep oversight over what students are up to and to (4) create scalable and reusable material. These experiences point to the need of striking a balance between project goals and the ideal situation on the one hand and matters of feasibility on the other. This balance necessitates compromising planning, designing, and implementing the feasibility of eight months' time. Hence, we opted to focus on the course design instead of the course facilitation in our first cycle of the transformation and developed simple guidelines which translate theoretical understanding and best practices of micro lectures, leaning objectives, or discussion prompts into hands-on manuals that are useful for subject matter experts when designing courses.

The generalisability of the insights from this project phase are subject to certain limitations. For instance, we cannot yet evaluate the efficacy of the taken measures to facilitate OTL in an international remote and on-site student group due to the early stage of the project. This, however, is part of the next project cycle and is already addressed by the instantiation of a continuous and low threshold feedback channel for students and instructors. Moreover, we plan to conduct formative and iterative evaluations throughout the coming test phase when the first online students enrol in courses. Another natural progression of this work would be to investigate the impact and usability of the guidelines for creating educational material that were created based on best practices and insights from research on online teaching and learning. Taken together, the endeavours of the current project kick off a shift in teaching and learning paradigms which require thorough institutional assistance and support for both instructors and students.

\section{REFERENCES}

Bailey, C. J., \& Card, K. A. (2009). Effective pedagogical practices for online teaching: Perception of experienced instructors. The Internet and Higher Education, 12(3-4), 152-155. https://doi.org/10.1016/j.iheduc.2009.08.002

Berge, Z. L. (2008). Changing instructor's roles in virtual worlds. Quarterly Review of Distance Education, 9(4), 407-415.

Bond, M., Buntins, K., Bedenlier, S., Zawacki-Richter, O., \& Kerres, M. (2020). Mapping research in student engagement and educational technology in higher education: a systematic evidence map. International Journal of Educational Technology in Higher Education, 17(2), 1-30. https://doi.org/10.1186/s41239-019-0176-8

Brame, C. J. (2016). Effective Educational Videos: Principles and Guidelines for Maximizing Student Learning from Video Content. CBE Life Sciences Education, 15(4). https://doi.org/10.1187/cbe.16-03-0125

Galikyan, I., \& Admiraal, W. (2019). Students' engagement in asynchronous online discussion: The relationship between cognitive presence, learner prominence, and academic performance. The Internet and Higher Education, 43, 1-9. https://doi.org/10.1016/j.iheduc.2019.100692

Garrison, D. R., Anderson, T., \& Archer, W. (1999). Critical Inquiry in a Text-Based Environment: Computer Conferencing in Higher Education. The Internet and Higher Education, 2(2-3), 87-105. 
Garrison, D. R., Anderson, T., \& Archer, W. (2001). Critical thinking, cognitive presence, and computer conferencing in distance education. American Journal of Distance Education, 15(1), 7-23. https://doi.org/10.1080/08923640109527071

Garrison, D. R., Cleveland-Innes, M., \& Fung, T. S. (2010). Exploring causal relationships among teaching, cognitive and social presence: Student perceptions of the community of inquiry framework. The Internet and Higher Education, 13(1-2), 31-36. https://doi.org/10.1016/j.iheduc.2009.10.002

Hung, M.-L., Chou, C., Chen, C.-H., \& Own, Z.-Y. (2010). Learner readiness for online learning: Scale development and student perceptions. Computers \& Education, 55(3), 1080-1090. https://doi.org/10.1016/j.compedu.2010.05.004

Jong, T. de (2010). Cognitive load theory, educational research, and instructional design: some food for thought. Instructional Science, 38(2), 105-134. https://doi.org/10.1007/s11251-009-9110-0

Ke, F. (2010). Examining online teaching, cognitive, and social presence for adult students. Computers \& Education, 55(2), 808-820. https://doi.org/10.1016/j.compedu.2010.03.013

Kebritchi, M., Lipschuetz, A., \& Santiague, L. (2017). Issues and Challenges for Teaching Successful Online Courses in Higher Education. Journal of Educational Technology Systems, 46(1), 4-29. https://doi.org/10.1177/0047239516661713

Martin, F., Ritzhaupt, A., Kumar, S., \& Budhrani, K. (2019). Award-winning faculty online teaching practices: Course design, assessment and evaluation, and facilitation. The Internet and Higher Education, 42, 34-43. https://doi.org/10.1016/j.iheduc.2019.04.001

McKenney, S. E., \& Reeves, T. C. (2012). Conducting educational design research. Routledge.

Molenaar, I., Sleegers, P., \& van Boxtel, C. (2014). Metacognitive scaffolding during collaborative learning: A promising combination. Metacognition and Learning, 9(3), 309-332. https://doi.org/10.1007/s11409-014-9118-y

Rubin, B., Fernandes, R., \& Avgerinou, M. D. (2013). The effects of technology on the Community of Inquiry and satisfaction with online courses. The Internet and Higher Education, 17, $48-57$. https://doi.org/10.1016/j.iheduc.2012.09.006

Star, J. R., \& Stylianides, G. J. (2013). Procedural and Conceptual Knowledge: Exploring the Gap Between Knowledge Type and Knowledge Quality. Canadian Journal of Science, Mathematics and Technology Education, 13(2), 169-181. https://doi.org/10.1080/14926156.2013.784828

Van der Meij, H., \& Carroll, J. M. (1995). Principles and Heuristics for Designing Minimalist Instruction. Technical Communication, 42(2), 243-261. https://www.ingentaconnect.com/content/stc/tc/1995/00000042/00000002/art00007

Vytgosky, L. S. (Ed.). (1978). Interaction Between Learning and Development.

Wiggins, G. P., \& McTighe, J. (2008). Understanding by design (1st ed,). Association for Supervision and Curriculum Development.

Wunderlich, A., \& Szczyrba, B. (2016). Learning-Outcomes 'lupenrein' formulieren. Zentrum für Lehrentwicklung, TH Köln. 